\title{
Elementos para pensar a transição agroambiental: as lógicas da mudança técnica na agricultura familiar
}

\section{Elements for reflections on agro-environmental transition: the logic of technical change in family farming}

\author{
Luciano de ALMEIDA*
}

\begin{abstract}
RESUMO
Este trabalho aborda as lógicas de escolha técnica dos produtores de hortaliças do município de ColomboPR. São analisadas práticas de intensificação produtiva no padrão convencional e técnicas de sistemas mais conservacionistas, tais como o uso reduzido de agrotóxicos e a agricultura orgânica. As dimensões econômica, sociocultural e ambiental são priorizadas na análise enquanto condicionantes das escolhas dos agricultores. Predomina em Colombo a combinação de solos frágeis com uma agricultura convencional, cujo manejo intensivo dos solos e uso de agroquímicos gera fortes impactos ambientais. Os agricultores fazem suas opções técnicas frente a um conjunto de restrições e oportunidades sinalizados ou efetivados pelo mercado, pela comunidade e por grupos de referência com os quais se articulam, pelo núcleo familiar, pelo meio físico, pelas estratégias técnicas e pelas instituições e serviços relacionados à gestão dos recursos naturais, à geração e à socialização de conhecimentos técnicos. É nesse contexto complexo e dinâmico que os agricultores se orientam, fazendo uso de sua lógica prática para se apropriar, ao seu modo, das opções técnicas e decidir como vão gerir os recursos naturais. Diante de diversas informações, necessidades práticas cotidianas, oportunidades e restrições, os agricultores reservam para si um campo de autonomia, onde desenvolvem processos de elaboração e filtragem. Com a integração ao mercado, a lógica econômico-instrumental ocupa, não sem resistência, um grau de importância cada vez maior, onde a dimensão econômica-mercantil, concretizada na maximização da produtividade e dos rendimentos, predomina na gestão. Valores sócioculturais, como segurança e autonomia, associados à agricultura familiar, surgem como outros elementos constitutivos dessas lógicas.

Palavras-chave: agricultura familiar; mudanças técnicas na agricultura; lógicas de gestão.
\end{abstract}

* Prof. Dr. do Departamento de Economia Rural e Extensão da Universidade Federal do Paraná, Curitiba, PR. 


\begin{abstract}
This paper discusses logics employed in the technical choices made by vegetable farmers in the municipality of Colombo, Paraná. Some practices for intensifying production that are developed through conventional systems as well as the techniques that are employed in more conservationist systems, such as those involving the reduced use of pesticides and fertilizers and organic agriculture are analyzed here. Economic, socio-cultural and environmental dimensions are emphasized as factors that determine farmers' choices. In Colombo, the combination of depleted soil and conventional agricultural practices prevail. Intensive use of soil and of chemical fertilizers and pesticides generate harsh environmental impact. Farmers have their technical choices based on a set of constraints and opportunities indicated by the market, by the community or reference groups. They are all connected through family, through the physical environment, through technical strategies and through institutions and services related to the management of natural resources and the generation and socialization of technical knowledge. It is within this complex and dynamic context that farmers seek a direction, guided by their own practical logic to get used to those technical options and make decisions on how to manage natural resources. In the face of diverse sources of information, daily practical needs and a series of opportunities and constraints, farmers preserve their own field of autonomy in which they develop processes of elaboration and filtering. With such integration into the market, economic and instrumental logic take on an ever-increasing importance. Notwithstanding some resistance, economic and market dimensions prevail, crystallized in efforts to maximize production and earnings. Socio-cultural values associated with family farming, such as security and autonomy, also emerge as other constitutive elements of the logic that is put into practice.

Key words: family farming; technical changes within agriculture; logic of management.
\end{abstract}

\section{Introdução}

Nas últimas décadas evidenciou-se a ampla magnitude dos impactos negativos do processo de modernização da agricultura sobre o meio ambiente e sobre a sociedade como um todo. $\mathrm{O}$ atual modelo de desenvolvimento agrícola, fundamentado na especialização da produção, no uso intensivo de insumos químicos, sementes geneticamente modificadas, máquinas e implementos, e na exploração intensiva dos recursos naturais, tem sido questionado diante das inúmeras evidências quanto a sua incapacidade de viabilizar economicamente a maioria dos agricultores, sobretudo os familiares, e permitir uma produção que não implique na acelerada degradação dos recursos naturais.

As áreas rurais próximas aos grandes centros urbanos apresentam freqüentemente uma realidade de agricultura intensiva baseada na produção de hortaliças, com fortes impactos ambientais associados principalmente à degradação dos solos e dos recursos hídricos. Ao mesmo tempo, em geral são áreas estratégicas quanto à captação e ao fornecimento de água para as populações urbanas, o que lhes confere, em particular, um histórico de tensões entre agricultores e intervenções institucionais e legais.

Os avanços tecnológicos e a necessidade de acompanhar a dinâmica do mercado têm levado à crescente intensificação da produção, com a utilização de áreas, apropriadas ou não em termos de aptidão agrícola, permitidas ou não, quando considerada a legislação ambiental. Diante da necessidade de incrementar crescentemente a produção e a produtividade, deu-se um processo de disseminação de práticas e uso de insumos que minimizavam impactos ambientais, tais como os riscos de contaminação com agrotóxicos. Adaptados, os agricultores incorporaram essa lógica produtivista, deixando arrefecer elementos importantes que garantiam, no passado, um melhor equilíbrio entre agricultura e a conservação dos recursos naturais. Nesse sentido, está a redução drástica da diversificação produtiva, substituída pela especialização na produção de hortaliças. Ao mesmo tempo, diminuem-se as criações, a produção de grãos e outras culturas para o auto-consumo. As áreas de mata são substituídas pela produção de hortaliças, que 
passa a ditar os ritmos da organização da produção. Nesse processo, conformam-se lógicas de gestão efetivadas em práticas agrícolas, nas quais onde eventuais preocupações ambientais dos agricultores têm um espaço limitado.

Dentro desse quadro, o aprofundamento dos problemas ambientais, além de outros de natureza social, tem levado a uma crescente pressão por um novo modelo agrícola, genericamente qualificado de "sustentável". Nessa orientação surgem propostas a favor de uma agricultura desenvolvida segundo princípios biológicos, operacionalizada através de um conjunto diverso de técnicas agrícolas que, de modo geral, procuram reduzir ou substituir insumos químicos, proteger o meio ambiente e a saúde e reforçar as interações biológicas e físicas nos agroecossistemas, no sentido dado a esse conceito por Gliessman (2000).

Essas técnicas e a intensidade com que elas são implementadas dependem dos pressupostos que orientam as propostas de alternativa à agricultura convencional. Nesse campo há um debate acirrado entre correntes que advogam a favor de uma agricultura ecológica, de redução de insumos, ou da pró-biotecnologia.

Esses processos estão construindo um ambiente no qual as relações entre agricultura e meio ambiente se revelam e são percebidas como conflituosas pelos agricultores. Supõe-se que estes apreendem as mudanças no contexto, seja como pressão ou oportunidade, o que pode levar a alterações nas formas de gestão dos recursos naturais e nas estratégias técnicas de produção agropecuária. As propostas de mudanças técnicas geradas e difundidas junto a essas populações pelas organizações ou instituições portadoras dessas outras formas de agricultura visam em parte estabelecer novas formas de apropriação e exploração dos recursos naturais. Isso pode implicar em alterações de diferentes proporções nas formas como esses grupos interagem com a natureza, como a percebem, produzem e exploram os recursos disponíveis para se reproduzir.

Contudo, a transição de um padrão agrícola convencional para outro fundamentado em princípios ecológicos tem se mostrado complexa e ainda limitada. Os condicionantes da mudança tecnológica nesse processo são de natureza variada e ainda pouco analisados. A identificação e a geração de práticas de produção de cunho conservacionista, particularmente da agricultura orgânica, enfrentam graves problemas de difusão e adoção. A análise dos condicionantes dessas restrições remete a uma revisão dos fundamentos balizadores da modernização da agricultura e do processo de mudança tecnológica no âmbito desta. Essa revisão orienta-se pelo pressuposto segundo o qual as questões relativas à transição para uma agricultura sustentável se fundamentam em instrumentais teóricos e metodológicos distintos daqueles que deram base à emergência e à consolidação da Revolução Verde.

Algumas versões da teoria da modernização que mais se difundiram entre agências de pesquisa e extensão agrícola foram as que tiveram em Schultz (1965) e em Rogers e Shoemerer (1971) suas principais referências teóricas e instrumentais e partem de um esquema que defende a incorporação de insumos e equipamentos de origem industrial na agricultura como principal mecanismo de desenvolvimento desta. Mais recentemente, autores como Haiami e Ruttan (1988) elaboraram o modelo de "inovação induzida", seguindo os mesmos pressupostos.

Segundo a teoria da adoção de Everett Rogers, todos os agricultores poderiam ser classificados entre "dinâmicos", mais propensos ao risco e receptivos às técnicas modernas, e agricultores "tradicionais", avessos ao risco e pouco receptivos àquelas técnicas. Essa teoria descreve um processo de decisão que abstrai o agricultor de seu contexto, supondo que a mudança tecnológica é uma decisão individual subordinada exclusivamente a características culturais e comportamentais.

As críticas a esse modelo em suas conseqüências sociais e ambientais já são bastante conhecidas. Mostrou-se que ele demandava um "perfill" de agricultor que excluía a grande maioria dos pequenos produtores familiares. A partir daí, desenvolveu-se um processo de investigação que procurava associar tecnologias "alternativas" ou "apropriadas", para citar apenas algumas adjetivações, às características de diferentes tipos de agricultores, particularmente o que na época era chamado de "pequena propriedade". Nessa trajetória, novos "fatores" de adoção e novos "perfis" de agricultores foram sendo construídos. Contudo, ainda eram limitadas as contribuições de novos pressupostos teóricos para orientar políticas de desenvolvimento que não utilizassem as noções difusionistas, e escapassem de uma visão estigmatizada dos agricultores enquanto receptores passivos de tecnologias geradas nos centros de experimentação.

Uma das contribuições mais positivas para essa mudança está na Teoria dos Sistemas Agrários, cuja elaboração é, em grande parte, encontrada nos trabalhos de Dufumier (1997) e Mazoyer (1992-1993) em oposição à Teoria da Modernização. A análise, em termos de sistemas agrários, reconhece e define os fatores históricos e geográficos responsáveis pela acumulação dos meios de produção e de diferenciação social 
dos agricultores. Nessa perspectiva, a tecnologia e sua capacidade de catalisar o desenvolvimento econômico têm de ser analisadas reconhecendo-se as necessidades específicas dos tipos de agricultores.

O reconhecimento da diversidade de agricultores e recursos disponíveis como balizador de políticas e estratégias de desenvolvimento tem se fortalecido com o advento do debate sobre a agricultura sustentável. Esse debate questiona a fragilidade do modelo da difusão de inovações e recoloca o problema da mudança tecnológica sobre uma nova perspectiva, que enfatiza a adequação dos processos de produção às condições reais presentes nos sistemas de produção.

Essas questões retomam a complexidade dos processos condicionantes da adoção da tecnologia, seja esta baseada em padrões convencionais ou orientados para a sustentabilidade agrícola. Nesse sentido, autores como Brandenburg (1999) e Guivant (1995) afirmam que, após a crítica aos pressupostos difusionistas da teoria da modernização, estabeleceu-se um vácuo quanto à análise dos condicionantes das mudanças tecnológicas orientadas para a sustentabilidade. A partir dessas questões, este texto analisa as lógicas que orientam essas escolhas produtivas, em especial a opção dos agricultores pela agricultura orgânica e por variações na intensidade do uso de agrotóxicos.

\section{Lógicas da mudança técnica}

Os trabalhos de Bourdieu permitem a compreensão de que os condicionantes macroestruturais da mudança tecnológica devem ser integrados a uma análise sobre a adoção como um elemento do senso prático dos agricultores, como base de suas estratégias mais amplas de reprodução social no espaço social em que buscam perpetuar-se (BOURDIEU, 1980 e 1989). A partir do conceito de habitus de Bourdieu, pode-se evitar uma análise estritamente objetivista ou subjetivista da relação sociedade-indivíduo, o que permite analisar tanto o caráter determinante das estruturas tecnológicas hegemônicas nas ações dos agricultores como seu espaço de criação e escolha.

As formulações da teoria da ação social, principalmente nos trabalhos de Touraine (1992), permitem, por outro lado, ressaltar a importância da compreensão dos significados que os agricultores atribuem à adoção e à implementação da tecnologia. Abrem, ainda, a possibilidade de se considerar os agricultores como atores sociais capazes de construir projetos de mudança.
Diferentemente das concepções difusionistas da Teoria da Modernização, esses pressupostos teóricos consideram o papel dos agricultores como sujeitos sociais, cujas decisões administrativas se dão dentro de múltiplas pressões, objetivos e expectativas em conflito. Ao mesmo tempo, se reconhecem os processos de elaboração, processamento, troca e reconstrução do conhecimento pelo agricultor.

Quanto a esse último aspecto, a teoria da ação social permite entender os agricultores adotando uma tecnologia ao seu próprio modo. De acordo com Guivant (1995, p. 123),

os agricultores não são "desviantes", "ignorantes" nem "vítimas" de um processo de difusão de um padrão tecnológico. (...) Os agricultores não assumem um papel passivo, mas construtivo: orientam-se segundo conhecimentos não só divergentes mas também contrários às instruções técnicas.

Essa ação adaptativa e inovadora pode ser entendida pela noção de "lógica prática" de Bourdieu (1980), em oposição à "lógica lógica”. A partir dessa noção, é possível dizer que os agricultores, enquanto atores sociais, constroem um espaço de cognitividade fundamentado em conhecimentos práticos, orientados por uma lógica prática. Essa lógica guia grande parte de suas escolhas e condutas e é capaz de gerar conhecimentos práticos significativamente diferentes dos conhecimentos técnicos e científicos.

Como afirma Brandenburg (1999, p. 236),

a implementação de técnicas leva o agricultor a pensar nas restrições naturais e sociais, ajustando estratégias que mais lhe convém. É nesses termos que o agricultor não é apenas ator social, mas também autor de atos técnicos.

Admite-se, ao mesmo tempo, que utilizar a perspectiva do ator social para analisar os processos de mudança tecnológica na agricultura pode contribuir para o entendimento dos significados que orientam as práticas dos agricultores.

Esses significados são diferentes entre agricultores de diferentes países ou de uma mesma região. De acordo com Guivant (1995, p.124), 
...aprofundar nessas especificidades é essencial para se conhecer o impacto da agricultura convencional, como também para pensar nas possibilidades de difusão e adoção de práticas agrícolas sustentáveis, já que não é meramente pelas evidências de sua viabilidade econômica, ou por estímulos macro-estruturais desenvolvidos de cima para baixo - como tem sido a tradição na difusão da agricultura moderna -, que os agricultores podem assumir os riscos e as vantagens de uma transição.

Ainda que essas questões sejam válidas, não se observa uma produção significativa sobre o tema no Brasil. Segundo essa mesma autora, no Brasil ainda são limitados os estudos das experiências orientadas para uma agricultura sustentável, no que diz respeito a uma análise das motivações dos agricultores.

Nessa perspectiva, este trabalho se insere no esforço para compreender os processos intervenientes na gestão das unidades de produção que possam apontar para a elaboração de modelos de produção e socialização de conhecimentos técnicos de caráter ambiental.

\section{Racionalidade e agricultura familiar}

Outro aspecto fundamental da abordagem teórica aqui adotada está relacionado à premissa da hegemonia da racionalidade econômica orientando as decisões dos agricultores.

O processo de "modernização da agricultura" e, no âmbito deste, os processos de mudanças técnicas, foram apresentados e difundidos dentro de uma perspectiva de racionalização da sociedade ocidental. Baseando-se em pressupostos de autoridade científica, materializados nas técnicas de produção e administração, buscou-se subordinar os processos produtivos e os comportamentos dos indivíduos a lógica do mercado.

Em nome da "modernização" da agricultura, tratou-se de classificar os agricultores em aptos e inaptos diante dos benefícios das mudanças ofertadas. A inaptidão é atributo de setores tidos como tradicionais, arcaicos, que resistem em manter e defender valores culturais, crenças e formas de organização antigas. Em defesa da racionalidade instrumental, era preciso que a agricultura se transformasse num negócio e que os agricultores se tornassem empresários, incorporando mecanismos contábeis, admitindo e internalizando a razão técnico-científica, incorporando como única orientação a lógica do lucro.
A análise neoclássica da produção agrícola utilizada para compreender a lógica que orienta as decisões-ações dos agricultores nesse processo de modernização tende a considerar a racionalidade econômico-instrumental como exclusiva, negligenciando a diversidade de estratégias e lógicas de decisão entre os agricultores. Para Silveira (1997), predomina na economia agrícola clássica a suposição de uma única racionalidade, a maximização da taxa de lucro, como orientadora dos agentes econômicos. Esse autor mostra ainda que essas análises partem de uma supremacia dos fatores econômicos orientando as estratégias de gestão dos agricultores, o que desconsidera condicionantes ecológicos, culturais e político-institucionais.

Entende-se aqui que o pressuposto da racionalidade econômico-mercantil como único parâmetro válido e universal para orientar as escolhas dos agricultores é incapaz de explicar a complexidade do processo de transição para uma agricultura sustentável. Essas noções vêm sendo desenvolvidas de longa data, motivadas, em parte, por um amplo debate sobre as especificidades da racionalidade do campesinato ou da agricultura familiar e sua pertinência nas sociedades capitalistas. Desde as concepções de Tchayanov (1990), até as análises mais recentes de Lamarche (1997), entre diversos outros autores, tem se desenvolvido uma abordagem em que se consideram os agricultores familiares tomando decisões num contexto complexo e conflituoso, no qual as decisões e escolhas são orientadas ao mesmo tempo pela racionalidade econômica e pelo progresso técnico e contra estes, impulsionados pelas necessidades de reprodução social da família, pelo desejo de liberdade, de autonomia, pelo exercício de suas crenças e pela prática de seus valores.

Essas noções implicam em admitir que, embora se concorde que o predomínio das relações mercantis tenha afetado todas as esferas da vida social, inclusive na agricultura, cabe ressalvar que as transformações em curso, em particular na agricultura familiar, não dissolvem outras relações sociais geradoras de lógicas diferenciadas da vida social.

Nesse sentido, são importantes as considerações de Lamarche (1997), para quem não faz sentido compreender todas as unidades de produção familiares como um único modelo, mas ao contrário, envolvendo situações extremamente diferenciadas. Baseado nesse pressuposto, esse autor sugere que as unidades familiares sejam analisadas em torno de um eixo definido pelo grau de integração à economia de mercado, ao qual corresponde uma certa relação com a sociedade de consumo, um certo modo de vida e um sistema de valores e de representação específico a ela. 
Nos extremos desse eixo de integração ao mercado estariam o "Modelo Original", que antecedeu e condiciona a situação do modelo de produção agrícola atual, e o "Modelo Ideal”, que representa a projeção futura do agricultor para sua unidade de produção, em função do qual estabelece estratégias e toma decisões. Em posições intermediárias a esses extremos estão as unidades de produção familiares, de acordo com a própria história e o ambiente específico no qual elas funcionam.

Um segundo eixo destacado por esse autor é definido em termos da importância do papel que a família exerce na organização da produção e nas formas de gestão agrícola, admitindo-se a existência de lógicas familiares de funcionamento diferentes.

A partir da seleção de critérios e indicadores do grau de integração ao mercado e da importância da família na unidade de produção, Lamarche (1997) identifica quatro modelos teóricos de funcionamento das unidades de produção familiares, destacando que estes são modelos apenas de referência, em direção aos quais há uma tendência. $\mathrm{O}$ "Modelo Empresa" caracteriza-se por relações de produção pouco (ou não) familiares e fortemente dependentes, nas quais os objetivos fundamentais são produzir para vender e realizar, senão o lucro, pelo menos um faturamento suficiente para remunerar corretamente sua força de trabalho. $\mathrm{O}$ "Modelo Empresa Familiar", no qual o trabalho organiza-se principalmente em torno da mão-de-obra familiar, o patrimônio é uma noção exclusivamente familiar e as estratégias são definidas em função de um futuro pensado em termos de reprodução familiar. Ao mesmo tempo, esse modelo é muito dependente do exterior, altamente integrado ao mercado, e a produção é pensada em termos de renda agrícola. O "Modelo de Subsistência", por sua vez, seria marcado pela forte predominância das lógicas familiares e uma fraca dependência em relação ao exterior. Nesse modelo, evidencia-se a prioridade da sobrevivência da família na lógica de gestão, à qual se associa o baixo nível tecnológico e a pouca produção. Por fim, o "Modelo Agricultura Familiar Moderna" seria marcado por uma lógica pouco familiar, mas também uma baixa dependência externa. Nesse modelo, ao mesmo tempo em que se procura reduzir o papel da família nas relações de produção, busca-se a maior autonomia possível.

Para o caso do município de Colombo, onde se desenvolveu esta pesquisa, os pressupostos desce modelo de análise foram elucidativos para caracterizar a diversidade de lógicas de gestão orientando as escolhas técnicas dos agri- cultores, em particular quanto às implicações dessas lógicas nos processos de conservação ou degradação ambiental.

Partindo dessa perspectiva, este trabalho procurou resgatar a complexidade das lógicas de gestão técnica dos agricultores modernizados de hortaliças, centrando-se na dimensão ambiental e na perspectiva de uma transição agroambiental no município de Colombo. Nesse sentido, associa-se ao esforço de se conhecer, a partir do reconhecimento da diversidade dos agricultores e realidades territoriais existentes no Brasil, a relação que aqueles têm com o meio ambiente, não só em suas práticas de produção, mas também nas racionalidades que se articulam com as escolhas técnicas e as orientam.

\section{Motivações para escolhas técnicas}

A análise das lógicas de gestão e do modo como elas se articulam para orientar as decisões dos agricultores foi desenvolvida a partir da interpretação das motivações dadas por estes para justificar suas escolhas. Essa análise mostra qual o significado que os agricultores atribuem às suas opções técnicas e a certas práticas de manejo dos recursos naturais. Entende-se que os agricultores fazem suas opções técnicas influenciados por fenômenos de ordem estrutural relacionadas ao contexto em que se inserem e, ao mesmo tempo, submetem tais opções a racionalidades próprias. Supõe-se, assim, que é preciso reconhecer aquele contexto, mas também analisar as mudanças a partir das escolhas e motivações desses agricultores.

Foi elaborado um quadro de análise que partiu da identificação das motivações/justificativas dadas pelos agricultores para as opções técnicas em uso, consideradas indicativas de distintas racionalidades. A escolha dessas opções foi prioritariamente orientada pela dimensão ambiental. Assim, foram analisadas algumas práticas sinalizadoras de sistemas mais conservacionistas, tal como variações na intensidade de uso de agrotóxicos e a agricultura orgânica, que são destacadas neste trabalho. Além dessas opções produtivas e técnicas, em Almeida (2003) pode-se encontrar a análise das variações na disponibilidade de recursos florestais, o manejo dos solos, a ocorrência do sistema hidropônico, o uso de estufas e irrigação, as opções por culturas agrícolas e a diversificação ou especialização produtiva. Em seu conjunto, essas opções são indicativas das lógicas que orientam a gestão da unidade como um todo e, algumas delas, podem revelar processos de inten- 
sificação tecnológica com implicações negativas para os recursos naturais e/ou alterações nas representações que os agricultores têm da natureza.

Nessa orientação, as lógicas de ação dos agricultores foram evidenciadas, inicialmente, a partir das justificativas para opções técnicas e para o manejo dos recursos naturais. Entretanto, um conjunto de procedimentos se articula para captar e compreender essas lógicas: questões específicas que indagam sobre as mudanças técnicas e as justificativas para tais, análise de valores, objetivos e constrangimentos associados às escolhas técnicas que permearam todo o diálogo desenvolvido durante o levantamento.

Quanto às justificativas ou motivações alegadas para as mudanças ou ao estágio atual das práticas e tecnologias, as respostas foram analisadas e categorizadas tematicamente a posteriori e, sempre que possível, adequadas a um quadro que as classificava entre dimensões ambiental - MA, econômica-ME, sociocultural-MSC, técnico-agronômica - MTA, físico-natural - CMF, legal - ML e outros - OUT, conforme Quadro 1.

\section{ESCOLHAS TÉCNICAS}

Agrotóxicos: por que usa mais, menos ou a mesma quantidade?

Herbicidas: por que não usa ou usa pouco?

Agricultura Orgânica: por que investiu?

\section{MOTIVAÇÕES}

MA / Motivação Ambiental: conservação dos recursos naturais; risco de degradação do solo (biologia do solo) pelo uso de herbicidas; histórico familiar de preservação.

MA: preocupação e/ou ética ambiental; percepção de risco dos agrotóxicos à saúde dos consumidores e/ou trabalhadores e/ou do solo e animais.

MA: preocupação com os riscos de uso de agrotóxicos para a própria saúde e da família.

ME / Motivação Econômica: manter ou ampliar a renda; falta de perspectiva de maior rentabilidade.

ME: reduzir ou manter custos de produção; evitar investimentos; falta de recursos; pagamento de dívidas.

ME: evitar ou reduzir custos com a contratação de mão-de-obra.

ME: opções, variações e exigência do mercado de hortaliças.

MSC / Motivação Sociocultural: desejo de autonomia e controle.

MSC: manter ou ampliar a segurança na reprodução da unidade; reduzir riscos.

MSC: melhorar qualidade de vida (moradia, saúde, educação, vestuário, condições de trabalho).

MSC: melhorar qualidade de vida (lazer, tempo livre).

MSC: aproveitamento da mão-de-obra familiar.

MSC: falta de mão-de-obra associada a restrições para contratação. 
MSC: preferência pessoal; costume, conhecimento e experiência.

ML / Motivação Legal / institucional: atender as leis, as normas de certificação; aproveitar incentivos.

MTA / Motivação Técnico-Agronômica: integração lavoura-pecuária.

MTA: associação de culturas e necessidade de rotações.

MTA: dependência da irrigação; dispensabilidade ou pouco uso da irrigação.

MTA: culturas e tecnologias (estufas) menos exigentes em agrotóxicos.

MTA: qualificação e aperfeiçoamento do controle de pragas e doenças.

MTA : sistema equilibrado que dispensa o uso de agrotóxicos.

MTA : demanda do sistema por agrotóxicos ou irrigação atendida.

MTA : indispensabilidade do uso de agrotóxicos.

MTA: maior ocorrência de pragas.

MTA: aumento das áreas de plantio na região; migração de pragas.

MTA: necessidade de pousio e/ou rotação de culturas.

MTA: uso reduzido de agrotóxicos.

MTA: controle manual e/ou mecânico de ervas daninhas (herbicidas).

MTA: desconhecimento de herbicidas específicos para hortaliças.

MTA: menor ocorrência de pragas e doenças.

CMF / Características ou restrições do Meio Físico natural: quantidade e qualidade de terra.

40. CMF: localização (distância) e/ou falta de água.

41. CMF: variações climáticas, pragas e uso de agrotóxicos.

42. OUTROS: pretende deixar a agricultura.

44. OUT: decisão influenciada por terceiros (orgânicos).

45. OUT: conhecimento de experiências positivas ou negativas com agricultura orgânica.

46. OUT: falta de informações sobre eficiência, produção e preços da agricultura orgânica.

47. OUT: julga ser impossível produzir sem agrotóxicos.

QUADRO 1 - ESCOLHAS TÉCNICAS E OPÇÕES DE RESPOSTA DAS MOTIVAÇÕES (conclusão)

FONTE: Adaptado de ALMEIDA (2003). 
Essas dimensões foram assim classificadas de modo a compreender a diversidade de lógicas que orientam as decisões dos agricultores. Elas são evidentemente uma simplificação das elaborações que constituem as racionalidades dos agricultores. Ao escolher ou justificar uma escolha, o agricultor tem em mente razões que não se separam por sua natureza econômica, ambiental ou técnica, entre outras. $\mathrm{O}$ que se observa é o contrário, as decisões dos agricultores consideram vários elementos, conscientes ou não, associados, com freqüência de maneira conflituosa.

A partir dessas justificativas, procurou-se identificar as pressões, as expectativas e os objetivos, freqüentemente em disputa, que orientam suas decisões administrativas, suas estratégias de gestão dos recursos naturais e suas escolhas técnicas. A análise das motivações utilizou como eixo condutor as distintas opções técnicas, de modo a discutir como as diferentes dimensões se destacam e se articulam para condicioná-las.

\section{As decisões dos agricultores: o uso de agrotóxicos e a agricultura orgânica}

\section{As dimensões econômica e sociocultural}

A história da agricultura no município de Colombo é um processo que parte de sistemas diversificados, fundamentalmente de subsistência, com elevado grau de autonomia em relação ao mercado. Progressivamente foram sendo incorporados novos padrões tecnológicos que resultaram, nos dias de hoje, numa agricultura onde predomina a especializada na produção de hortaliças, fundamentalmente voltada para o mercado e que ocupa aceleradamente o espaço dos produtos cultivados nas propriedades para o consumo da família.

A agricultura no município constituiu-se, assim, ao longo do tempo, em uma atividade altamente integrada e dependente do mercado. Isso fez crescer uma lógica mercantil e produtivista na gestão das unidades. Ainda que não exclusiva, é essa lógica, operacionalizada na busca de maiores rendimentos, que crescentemente orienta as opções técnicas dos agricultores. A busca pela redução de custos, as mudanças produtivas e técnicas orientadas por oportunidades de mercado e de ampliação de rendimentos se expandem para orientar a gestão da unidade e dos recursos naturais.
Ao mesmo tempo, as comunidades rurais de Colombo são marcadas por uma história e uma trama social que revelam estratégias sociais e organizacionais distintas dos padrões urbanos. Mesmo que fortemente influenciadas pelas dinâmicas da expansão urbana e de atividades não-agrícolas, as opções técnicas estão, em grande parte, associadas à inserção dos agricultores na dinâmica das redes econômicas e socioculturais construídas ao longo de mais de um século, a partir da chegada dos imigrantes, predominantemente italianos.

Há um rural que se espalha pelo município, no qual a agricultura familiar historicamente instalada está no centro de uma vida social intensa. Existem núcleos de agricultores familiares que, com níveis variados de capitalização e/ou intensificação da produção, conformam uma trama socioespacial dinâmica no município. A produção de hortaliças ocorre num ambiente constituído pela história da imigração e das trajetórias econômicas e socioculturais dos agricultores familiares, configurando redes de relações, padrões e valores socioculturais que fazem a diferença nas escolhas técnicas e na conformação das lógicas de gestão das unidades.

Nessa perspectiva, passado e tradição não são entendidos como elementos culturais estigmatizados pela associação com um suposto "atraso" ou "resistência" a mudanças técnicas. A noção de habitus de Bourdieu, mais uma vez, é propícia para a reconfiguração e a análise das trajetórias dos indivíduos, conformando um campo dentro do qual se dão as escolhas destes. Ou seja, a "escolha" do agricultor é precedida de uma história que, de forma desigual, distribui capital social e econômico que, por sua vez, limita o leque das opções técnicas.

Nessa perspectiva, pode-se apreender que as lógicas que orientam a gestão das unidades devem ser analisadas a partir de suas articulações com trajetórias (fundiária, demográfica/familiar, produtiva, ecológica), com a história do grupo que a constitui e com objetivos e projetos que essas lógicas alimentam.

O acesso ao capital social e econômico construído nessa história pode restringir ou potencializar oportunidades produtivas e opções tecnológicas. A agricultura orgânica situa-se nesse quadro. Ao mesmo tempo, as relações de parentesco, fortemente constituídas, freqüentemente viabilizam a produção e comercialização, além de constituírem fonte de recursos para investimentos e principalmente para o pagamento de eventuais dívidas. 
Além disso, o uso de agrotóxicos pela grande maioria dos agricultores mostra que o contexto sociocultural constitui-se num campo que legitima essa escolha, entre outras práticas comuns.

Destaca-se ainda que, em diferentes situações e opções técnicas os agricultores, ao atribuírem sua significação própria, tomam suas decisões baseados em necessidades de segurança, autonomia e qualidade de vida, mostrando que a reprodução do grupo familiar tem papel fundamental. Nesse sentido, está o uso de agrotóxicos. Sua aplicação, muitas vezes preventiva, reduz os riscos de perdas decorrentes de pragas e doenças e garante, pelo menos na percepção do agricultor, a produção e a renda desejada.

Essas considerações reafirmam que se mantém em Colombo uma agricultura de base familiar influenciando as opções tecnológicas. A disponibilidade e qualidade da mão-de-obra familiar, ainda que em diminuição, constituise em vantagem relativa que favorece certas opções, entre elas a própria produção de hortaliças. Ao mesmo tempo, valores relacionados à manutenção do patrimônio, da autonomia, da minimização de riscos, entre outros, ainda que em transformação, influenciam as decisões dos agricultores. Ao mesmo tempo, a atual agricultura familiar produtora de hortaliças revela significativas transformações em seu percurso, entre as quais a expansão de uma lógica mercantil já destacada.

Essas lógicas têm implicações variadas em se tratando dos reflexos ambientais das práticas que elas orientam. $\mathrm{O}$ universo sociocultural associado à agricultura familiar, em alguns casos, alimenta o processo de intensificação tecnológica e produtiva do padrão convencional, acirrando riscos e impactos ambientais. A associação entre o uso de agrotóxicos e/ou da irrigação intensiva e o desejo de minimizar riscos, ampliando garantias de reprodução da unidade, é um exemplo dessa correlação.

No sentido oposto, a preocupação de minimizar riscos leva muitos agricultores a optar por reduzir custos de produção, o que, em Colombo, geralmente está associado à redução no uso de agrotóxicos.

O desejo de resguardar um campo de autonomia na gestão do tempo e nas decisões cotidianas do fazer agrícola constitui-se num valor que também ilustra essa dupla, e ambígua, correlação com a dimensão ambiental. O manejo dos agrotóxicos, realizado em meio à falta de orientações, mas condicionado a um modo particular de uso, tem levado à ampliação de riscos de contaminação seja do agricultor, seja dos consumidores e dos recursos hídricos.
$\mathrm{O}$ avanço de uma lógica mercantil e produtivista, por sua vez, legitima a intensificação produtiva no modelo convencional, o que tende a acirrar processos de degradação dos solos, de exploração de áreas antes reservadas para florestas e de contaminação pelo uso de agrotóxicos. Esse é um fenômeno dado pela dinâmica atual dos sistemas de produção de hortaliças altamente integrados ao mercado. As pressões para a intensificação produtiva tendem a ser mais efetivas que aquelas advindas do contexto ambiental ou de preocupações próprias de caráter conservacionista.

É necessário lembrar, por outro lado, que a opção pela agricultura orgânica também é prioritariamente motivada pelo desejo de ampliar a renda. Essa motivação econômica, ainda que imbricada nas necessidades socioculturais, revela que, em Colombo, essa opção técnica mais conservacionista está associada à lógica mercantil que a orienta. Nesse sentido, trata-se de uma opção técnica que se constitui numa estratégia de adaptação a circunstâncias econômicas e mercadológicas.

\section{A dimensão ambiental}

O uso de agrotóxicos é amplamente disseminado e legitimado para a maioria dos produtores. Ao longo de quatro décadas de incentivos e uso intensivo, os agroquímicos constituíram-se em sinônimo de agricultura. Isso se dá num contexto em que se desconhecem e/ou se relativizam as implicações ambientais do uso de agnotóxicos.

É complexo o universo simbólico associado ao uso de agrotóxicos. Constitui-se um contexto ambíguo, retratado no discurso dos agricultores: ao mesmo tempo em que alguns reconhecem as pressões e os riscos, reafirmam a indispensabilidade dos agrotóxicos. Para os que reduzem o uso de agrotóxicos, principalmente herbicidas, a preocupação ambiental se restringe predominantemente ao pragmatismo da percepção de riscos em relação à própria saúde do agricultor e de seus familiares. Preocupações ambientais relacionadas com os consumidores e com a contaminação dos recursos naturais surgem eventualmente com caráter secundário.

Embora o contexto de pressões e restrições de caráter ambiental sobre a agricultura seja uma realidade, e os agricultores tenham amplo conhecimento deste, não se percebe que esse processo tenha sido capaz de fazer da dimensão ambiental um elemento motivador expressivo das escolhas técnicas, de modo a alterar as práticas agrícolas conven- 
cionais consolidadas. Ao menos no que tange à percepção dos riscos do uso de agrotóxicos, da degradação dos solos e à efetiva implementação de medidas de precaução, tal preocupação é muito limitada. Quando essas mudanças ocorrem, é a necessidade de reduzir custos e/ou ampliar as opções de mercado e renda que estão predominantemente em suas origens.

Disso se deduz que há uma longa distância entre um discurso da maioria dos agricultores sintonizado com alguns riscos, regras e restrições ambientais e as práticas agrícolas dominantes, de forte impacto ambiental. A preocupação ambiental e a percepção dos riscos ecológicos decorrentes do modelo agrícola em curso, além de restritas, não têm correspondência, na mesma proporção, na incidência de práticas conservacionistas.

Quando se aborda a opção pela agricultura orgânica, não se identificou no conjunto dos agricultores orgânicos a presença de uma preocupação conservacionista que fosse além do pragmatismo do risco com a própria saúde, como elemento importante motivando o abandono da agricultura convencional. Revelou-se que os agricultores orgânicos priorizam a lógica mercantil na orientação dessa opção tecnológica, o que exclui a preocupação ambiental como principal elemento motivador da mudança. Dessa forma, tal como outros padrões tecnológicos em Colombo, a agricultura orgânica é predominantemente uma estratégia de adaptação a circunstâncias econômicas e mercadológicas, motivada pelo desejo de auferir maiores rendimentos e, em menor freqüência, resultado da preocupação pragmática com os riscos de uso de pesticidas para a própria saúde.

Esses dados revelam que, para o caso específico da agricultura orgânica, não há uma correlação inflexível entre padrão tecnológico e lógicas de gestão. Ou seja, a transição para uma agricultura mais conservacionista pode se dar dentro de uma lógica prioritariamente mercantil, ainda que se possa discutir os limites ecológicos e socioeconômicos de tal mudança.

\section{Lógicas em coexistência}

A partir do conceito de habitus de Bourdieu (1980), é possível compreender como as trajetórias do conjunto dos indivíduos constituem um campo dentro do qual se dão as possibilidades de escolhas. Em Colombo, há uma história que, de forma desigual, distribui capital social e econômico, limitando o leque das opções técnicas. Nesse contexto sociocultural, se constroem redes de sociabilidade e poder que conformam campos de legitimidade a orientar as escolhas dos agricultores. Admite-se assim, como Darré (1999, p. 149), que "as 'racionalidades' da vida cotidiana se constroem na interação, nos grupos sociais, e é dentro destes grupos sociais que se verifica, pelos sujeitos, a validade das escolhas".

Contudo, esses elementos objetivos e do ambiente social não condicionam exclusivamente as opções técnicas dos agricultores de Colombo. Tal como afirma Guivant (1995, p. 121), "toda prática social apresenta simultaneamente tanto um aspecto reprodutivo das relações sociais dominantes como também produtivo de novas relações". Frente àquele contexto turbulento e dinâmico de estruturas e processos coercitivos, os produtores de hortaliças se orientam para se apropriar, ao seu modo, das opções técnicas e decidir como vão gerir os recursos naturais.

Diante de diversas informações, necessidades cotidianas, oportunidades e restrições, os agricultores se baseiam em conhecimentos práticos, orientados por uma lógica prática, para fazer suas escolhas. Essa noção admite ainda, a partir das considerações de Dubet (1995), que os indivíduos/agricultores combinam diversas lógicas em sua prática cotidiana. Nesse sentido, a pesquisa mostrou a pluralidade de lógicas de ação que coexistem nas experiências dos indivíduos. Cada agricultor combina continuamente várias lógicas de natureza diversa, nas quais coexistem as dimensões econômica, sociocultural, legal, técnico-agronômica e ambiental.

Destacou-se a análise do modo como os agricultores freqüentemente orientam suas escolhas, ao mesmo tempo pela razão instrumental (a racionalidade econômica e o progresso técnico) e contra esta, orientados pelo desejo de segurança, autonomia e liberdade, pelo exercício de suas crenças e pela prática de seus valores. A partir das análises das motivações associadas principalmente ao uso de agrotóxicos, verificouse que os produtores de hortaliças de Colombo, enquanto agricultores inseridos fortemente na lógica mercantil, buscam ampliar rendimentos. Enquanto agricultores familiares historicamente inseridos numa dinâmica rural local, desejam garantir a reprodução do núcleo familiar e do patrimônio, reduzindo custos, minimizando riscos, valorizando campos de autonomia e legitimação social.

Ao mesmo tempo, as motivações apresentadas para várias opções técnicas mostraram os agricultores decidindo frente a um leque amplo de condicionantes de natureza diversa. Isso não significa, entretanto, que alguns elementos não ganhem destaque frente a determinadas opções. 
O processo de intensa integração ao mercado, ao qual os agricultores analisados vêm gradativamente se submetendo há mais de um século, configurou lógicas de gestão nas quais a dimensão econômica, concretizada na ampliação da produtividade e da renda e na preocupação com a manutenção e/ou ampliação de mercados, é cada vez mais valorizada. Se for verdade que as motivações de natureza econômica se destacam, isso não significa, entretanto, que se possa afirmar a sua exclusividade na orientação das escolhas técnicas e no modo como os agricultores de Colombo fazem a gestão dos recursos naturais.

Uma primeira observação relevante é que as lógicas, em suas diferentes dimensões, não são independentes ou autônomas. Ao contrário, a noção de coexistência pressupõe que elas freqüentemente estão imbricadas uma na outra.

Um outro aspecto necessário de ser apontado diz respeito à hierarquia entre as dimensões nas lógicas de gestão. Nesse sentido, cabe resgatar as considerações de Dubet (1995), a partir das quais é possível entender os agricultores frente a um universo complexo orientando suas lógicas, de tal forma que as relações de preponderância são instáveis. Entende-se que não há uma hierarquia ou coerência implícita na forma como diferentes elementos e/ou dimensões se relacionam para conformar as lógicas. Freqüentemente essas relações parecem ambíguas e controversas, revelando o contexto de pressões e necessidades práticas cotidianas no qual o agricultor tem que tomar suas decisões.

Novamente, é pertinente considerar o conceito de lógica prática, que, segundo Bourdieu (1980), tem por princípio um sistema de planos geradores e organizadores objetivamente coerentes, funcionando, no "sentido prático", como um princípio de seleção freqüentemente impreciso, mas sistemático. Ela não tem o rigor e a constância que caracterizam a lógica, capaz de deduzir a ação racional de princípios explícitos, controlados e sistematizados num axioma.

Entende-se assim que, frente a múltiplos condicionantes de natureza diversa, os produtores de hortaliças de Colombo fazem uso de sua lógica prática para decidir cotidianamente, sem que se possa atribuir a uma única lógica ou à predominância estável de uma dessas a orientação do conjunto de suas escolhas.

\section{Considerações finais}

As escolhas e decisões, em particular o uso de agrotóxicos e a agricultura orgânica, revelam lógicas caracteri- zadas pela coexistência de orientações diversas constituídas em processos de mudança que articulam sujeito e contexto. Essas lógicas são influenciadas por fatores diversos e controversos, conformando um quadro no qual não há uma única lógica a orientar a relação com o meio ambiente e as decisões de agricultores.

Ao mesmo tempo, as lógicas de gestão técnica dos produtores de hortaliças de Colombo incorporam diferentes dimensões: econômica, sociocultural, técnico-agronômica, legal e ambiental. Dado o processo de intensa integração ao mercado, vem se configurando uma lógica econômica instrumental de gestão na qual a dimensão econômica, evidenciada pela busca de maior produtividade e renda, ocupa, não sem resistência, um grau de importância cada vez maior. Ao mesmo tempo, a existência de valores socioculturais como segurança e autonomia, que mostram outros elementos constitutivos dessas lógicas.

Essas análises ilustram o modo como os agricultores fazem suas escolhas, organizam o trabalho e a produção de modo a reproduzir as unidades. A lógica do lucro e a racionalidade instrumental não se expandem de forma inexorável na agricultura. $\mathrm{O}$ universo no qual os agricultores tomam suas decisões é muito mais rico e complexo do que a visão mecanicista e simplificada de uma empresa tentando maximizar a produção e os rendimentos.

Ao mesmo tempo entende-se que é preciso admitir e não adjetivar negativamente a "desordem", ou a aparente "falta de coerência", na dinâmica das decisões dos agricultores. Observa-se que as dimensões econômica, social, cultural e política se imbricam, se entrelaçam, e freqüentemente se confundem nas lógicas de gestão. Para Dubet (1995), cada indivíduo combina continuamente várias lógicas de natureza diversa, sem uma hierarquia ou sucessão constante entre elas. As noções de lógica prática de Bourdieu parecem ser as mais adequadas para entender os agricultores decidindo em meio a um cotidiano permeado de necessidades práticas e orientado por estratégias diversas, que mudam freqüentemente.

Reconhecer essa natureza dos processos decisórios, ou seja, admitir um campo de autonomia, no qual os agricultores aplicam sua marca pessoal nas escolhas e na gestão da unidade, não significa desmerecer os condicionantes externos. Mas sim apontar para que, reconhecendo aquela relativa autonomia, se minimize a capacidade persuasiva e determinante de elementos e agentes externos e se reconheça que são os agricultores que decidem. 
Por fim, é necessário destacar que, entre a preocupação ambiental e a adoção efetiva de técnicas conservacionistas, há um cotidiano complexo em que os agricultores se desdobram entre necessidades práticas de diversas dimensões, sejam elas associadas às características e à dinâmica dos sistemas de produção, sejam de ordem econômica ou sociocultural. São estratégias que adquirem primazia nas lógicas de gestão, ainda que isso resulte em riscos ambientais, conscientes ou não.

Embora isso possa parecer fatalista, não esconde um processo dinâmico de mudanças capaz de transformar valores e a gestão dos recursos naturais. $\mathrm{O}$ avanço da agricultura orgânica observado recentemente aponta nesse sentido. No caso do município em estudo, alguns fatores se articulam positivamente para essa mudança. A crescente pressão e fiscalização pelo uso racional do solo e dos

\section{Referências}

ALMEIDA, L. de. Mudança técnica na agricutura: perspectivas da transição ambiental em Colombo - PR. Curitiba, 2003. 294 f. Tese (Doutorado) - Universidade Federal do Paraná.

BOURDIEU, P. Le sens pratique. Paris: Les Éditions de Minuit, 1980.

BRANDENBURG, A. Agricultura familiar, ONGs e desenvolvimento sustentável. Curitiba: Ed. da UFPR, 1999.

Movimento agroecológico: trajetória, contradições e perspectivas. Desenvolvimento e Meio Ambiente: caminhos da agricultura ecológica. Curitiba, Editora UFPR n. 6, p. 11-28, 2003.

DARRÉ, J. P. La production de connaissance pou l'action. Paris: Éditions de la maison des ciences de l'homme, Institut National de la Recherche Agronomique, 1999.

DUBET, F. Sociologique du sujet et sociologie de l'expérience. In: DUBET, F.; WIEVIORKA, M. (direction). Penser le sujet: autour d'Alain Touraine. France: Fayard, 1995.

DUFUMIER, M. Les projets de développement agricole: manuel d'expertise. Paris: Karthala, 1997.

GUIVANT, J. S. A agricultura sustentável na perspectiva das ciências sociais. In: (Org.). Meio ambiente, desenvolvimento e cidadania: desafios para as ciências sociais. São Paulo: Cortez; Florianópolis: Universidade Federal de Santa Catarina, 1995. p. 99-133. agrotóxicos, bem como a exigência de responsabilidade técnica na produção agrícola, ampliam a percepção dos agricultores quanto aos impactos ambientais da agricultura convencional. Por outro lado, há a crescente propaganda favorável à agricultura orgânica e as boas perspectivas de mercado evidenciadas pelo aumento no número de agricultores que fazem a conversão para esse sistema. Um outro fator importante é a crise nas unidades de produção, cujas características, sobretudo físico- naturais e de tamanho dos estabelecimentos, inviabilizam a continuidade da produção intensiva de hortaliças no sistema convencional. A queda de produtividade e o aumento dos custos de produção ajudam a construir um cenário negativo para os pequenos agricultores familiares, que vêem na redução do uso de agrotóxicos ou na agricultura orgânica opções para reduzir custos e ampliar a renda.

HABERMAS, J. Técnica e ciência como ideologia. In: Os pensadores. São Paulo: Abril Cultural, 1975.

HAIAMI, Y.; RUTTAN, V. Desenvolvimento agrícola: teoria e experiências internacionais. Brasília: Empresa Brasileira de Pesquisa Agropecuária, 1988.

LAMARCHE, H. (Coord.). A agricultura familiar: comparação internacional. 2. ed. Campinas: Editora da UNICAMP, 1997. v. 1: Uma realidade multiforme. Trad. de: Angela M. N. Tijiwa.

MAZOYER, M. Pour des projets agricoles légitimes et éfficaces: Théorie et méthodes d'analyse des systèmes agraires. Roma: FAO, 1992-1993.

ROGERS, E.; SHOEMERER, F. Comunication of innovations. 2. ed. New York: The Free Press, 1971.

SCHULTZ, T. A transformação da agricultura tradicional. Rio de Janeiro: Zahar, 1965. 